\title{
Genetic dissection of stage-dependent dry matter accumulation in Maize (Zea mays L.) kernel
}

\author{
Jianju Liu \\ China Agricultural University \\ Hui Yu \\ China Agricultural University \\ Baoshen Liu \\ Shandong Agricultural University \\ Mingliang Xu \\ China Agricultural University
}

Saihua Chen ( $\nabla$ chensaihua@yzu.edu.cn )

Yangzhou University https://orcid.org/0000-0003-0073-8446

\section{Research Article}

Keywords: Maize, grain, dry matter accumulation, grain yield

Posted Date: January 17th, 2022

DOI: https://doi.org/10.21203/rs.3.rs-1163629/v1

License: () (i) This work is licensed under a Creative Commons Attribution 4.0 International License. Read Full License 


\section{Abstract}

Dry matter accumulation (DMA) in kernels is a fundamental requirement for high grain yield maize breeding and harvesting. However, the genetic mechanism underlying how DMA promotes the grain weight at different grain-filling stages is poorly understood. Here, with a recombinant inbred line (RIL) population, we performed a quantitative trait locus (QTL) analysis of DMA during the early and late grain-filling stages under three environmental conditions. Taking 0-45 days after pollination (DAP) as a minimum period to physiological maturity, we investigated the DMA before 45 DAP, designated $\mathrm{DMA}_{0-45}$, and found that 13 DMA QTLs are responsible for $\mathrm{DMA}_{0-45}$ and each could explain 7.11 to $23.64 \%$ of the total phenotypic variation. Of them, four QTLs, qDMA5.2, qDMA6.4, qDMA7.2, and qDMA9.2 were consistently detected in at least two of three field trials. For the DMA after 45 DAP, 18 QTLs were detected and they could account for 8.49 to $28.66 \%$ of the total phenotypic variation and only qDMA1.2 was consistently detected at Shandong for two years continuously. Since no common DMA QTL was found between the early (0-45 DAP) and the later (after 45 DAP) stage, it is speculated that the genetic control of DMA acts in a stage-dependent manner. Our results will be helpful to further decipher the genetic basis of grain yield formation and provide a sight for grain yield improvement in maize.

\section{Introduction}

Yield is one of the essential breeding objectives in maize (Ku et al. 2010) and it is an extremely complex trait and depends on four essential components: planting density, rows per ear, kernels per row, and kernel weight. As one of the most important factors, kernel weight depends mainly on the dry matter accumulation (DMA) in kernel, which is a dynamic process after pollination. The DMA process in kernel can be roughly divided into three phases, including the initiation, grain-filling period and physiological maturity (PM) stages and the kernel weight follows a S-shaped growth pattern (Borrás et al. 2009). During the grain-filling period, the dry matter keeps increasing until the PM stage which is marked by the disappearance of the milk line and the formation of a black layer (Bewley 1994; Gambín et al. 2008). Once maize kernels come to the PM stage, their dry matter will no longer be accumulated. Therefore, DMA at PM stage always determines kernel weight and finally affects maize grain yield.

Previous studies have shown that the period from silking to PM stage varies in different inbred lines. Generally, the PM stage appears during 45 to 50 days after silking in mid-early inbred lines, while it needs 50 to 60 days to reach at in the mid-late inbred lines. The length of the period to PM stage reflects the time spent on grain filling, which is a key factor of DMA and always be indicated by grain filling duration (GFD). Apart from GFD, grain filling rate (GFR) is another factor that shows the speed of DMA before PM stage. GFD and GFR together affect the DMA and determine the kernel size, weight, and eventually corn grain yield (Li et al. 2005). It seems that GFD extension combined with GFR enhancement will promote the formation of grain yield. However, it has been reported that GFR is negatively correlated with GFD (Wang et al. 1999). A delayed PM, resulted from an extension of GFD rather than a change in flowering date, decreased the GFR and caused higher grain water content at harvest (Wang et al. 1999). Furthermore, PM delay caused by GFD extension also leads to kernel germination and ear rot, reducing grain yield and quality during mechanical harvesting (Baute et al. 2002; Kebebe et al. 2015; Geng et al. 2016). By contrast, hybrids with faster GFR have a relatively higher grain dehydration rate, as there is a positive correlation between GFR and grain moisture loss (Kang et al. 1986). Instead of prolonging GFD, increasing GFR to accelerate DMA at an early stage of kernel development will be an effective way to increase grain yield without compromise in mechanical harvesting (Gasura et al. 2013).

Many quantitative trait loci (QTL) related to grain weight have been identified. For instance, two heterotic loci and 51 digenic interactions were detected based on a single $\mathrm{IF}_{2}$ population (Tang et al. 2010). Seven QTLs were detected by a set of $231 \mathrm{~F}_{2: 3}$ families derived from Zheng58 and Chang7-2, and the genetic variation explained by a single QTL ranged from 6.43 to $28.16 \%$ (Guo et al. 2011). With multiple RIL populations, a total of 146 major QTLs with $R^{2}>10 \%$ in at least one environment were detected, among which Lqkwei4 was stably expressed in four environments with a maximum $R^{2}$ of $27 \%$ (Li et al. 2013). qKW7, a major QTL for kernel weight and kernel width was fine-mapped to a $647-\mathrm{Kb}$ interval by the combined analytic approaches of linkage and association analysis (Li et al. 2016). A major QTL $q K W-9.2$ was narrowed down from $1.68 \mathrm{Mb}$ to $630 \mathrm{~Kb}$, harboring 28 putative candidate genes (Raihan et al. 2016). Though many QTLs related to final grain weight have been identified, whether they promote the grain weight by speeding up GFR or by prolonging GFD is largely unknown. Likewise, some genetic loci involved in GFR have been revealed. Twentythree unconditional QTLs and nine conditional QTLs for GFR were identified by using a set of 203 RILs (Liu et al. 2011). Thirty-three different unconditional QTLs and fourteen conditional QTLs for GFR were detected, among which $q Q T L 7 b$ and $q Q T L 6 f$ were identified at the same stage of development (Zhang et al. 2013). A total of 90 non-redundant QTLs were identified with respect to 12 
characteristic parameters involved in seed filling, which were estimated by seed dry weight at 14 time points after pollination (Yin et al. 2020). However, whether these QTLs act on DMA at appropriate stages and finally contribute to grain weight is still elusive.

A simple but effective method to decipher the genetic composition of maize kernel weight associated with high GFR at early stage is to identify the QTL of DMA within a limited period after pollination. In our previous study, we investigated dynamic DMA patterns of four RILs after synchronous pollination and found an obvious divergence of DMA before and after 45 DAP. From 20-45 DAP, all four RILs displayed an almost linear accumulation pattern, while RIL3 and RIL4 had much higher DMA than RIL1 and RIL2. However, the DMA tendency was changed thereafter: one was stagnant, another slowed down and the others two continued to increase. These results suggested that DMA varies among different RILs and their DMA gaps may occur at either early or late stages of grain filling (Liu et al. 2020). In this study, we attempt to identify the DMA QTL at early and late stages, respectively. These DMA QTLs acting at early but not late stage would be more recommended to corn breeders. Taking 45 days as a minimum period to physiological maturity, we divided the whole grain filling duration into two types of stages, including the early stage, that is $0-45$ days after pollination, and three late stages which includes 45-50, 50-55, 55-60 days after pollination. By investigating the DMA at each stage (designated DWA $A_{0-45}$, $D_{W} A_{45-50}, D A_{50-55}$ and $D_{W A} A_{5-60}$ ), we found significant differences of DMA among parent lines and their derived RIL population at all stages and suggested a stage-dependent formation of maize kernel weight through QTL analysis. Our results will shed light to highyield corn breeding with suitable physiological maturity period and no compromise to mechanical harvesting.

\section{Materials And Methods}

\section{Plant materials}

The initial RIL population was provided by Prof. Baoshen Liu of Shandong Agricultural University, which consists of $362 \mathrm{~F}_{12}$ RILs developed from a cross between inbred lines 844 (higher DMA) and 807 (lower DMA). The RIL population was used to perform the QTL mapping of DMA for two stages: an early stage which is 0-45DAP and late stages which represent 45 DAP to final harvest. To obtain accurate phenotypic data for various RILs, we first recorded the flowering time for each RIL and chose those RILs that have similar silking stages to ensure simultaneous pollination.

The RIL population was investigated for dry matter accumulation in three field trials. In the summer of 2014, 94 RILs were evaluated for DMA at 0-45 and 45-50 DAP, namely $\mathrm{DMA}_{0-45}$ and $\mathrm{DMA}_{45-50}$, in the research station of Shandong Agricultural University (Taian, Shandong). In the winter of 2014, 134 RILs (including the above-mentioned 94 RILs) were sown in Hainan (Jiusuo, Hainan) and $D_{M A}-45$ and $D_{M A} 5-50$ were investigated. In the summer of 2015 , the same set of 134 RILs was repeatedly planted at the research station of Shandong Agricultural University and DMAs at 45, 50, 55 and 60 DAP were surveyed, respectively.

\section{Field planting}

A completely randomized plot design with two biological replicates was implemented for each field trial. Seventeen kernels were sown in a 4.0-m row, spacing between adjacent plants was $0.25 \mathrm{~m}$, and the distance between adjacent rows was $0.8 \mathrm{~m}$. Standard field management was implemented to reduce the influence of environmental conditions on plant growth.

\section{Synchronous pollination}

The baby ears were covered with sulfate paper bags before silking to prevent them from open pollination. Due to the different pollen viability of the RILs, it was impossible to allow self-fertilization of all the RILs in a single day. So, when $90 \%$ plants of each RIL were silking, we collected pollen from the parental line 807 to pollinate all RILs simultaneously. We later sampled the ears of each RIL that were fertilized at the same day to measure the dry matter accumulation. The ears with uneven kernel set due to partial pollination were discarded. It was ensured that all ears from different RILs were at the same developmental stage to minimize the influence of environmental conditions on kernel development during grain development.

\section{Analysis of phenotypic data}

For phenotyping, we harvested three to four ears of each line at 45, 50, 55 and 60DAP, respectively. We then collected the kernels in the middle part of ears. As one repeat, 100 kernels from a single RIL were placed in a craft paper bag and dried in a forced-hot-air dryer at $105^{\circ} \mathrm{C}$ for 10 minutes, followed by drying at $80^{\circ} \mathrm{C}$ to a constant weight. The dried kernels were weighed to obtain Grain Dry Weight (GDW) at each time point. 
Microsoft Excel 2019 and R project (www.R-project.org) were used to perform statistical analyses. A correlation coefficient ( $r$ ) of the two different phenotypes, $\mathrm{DMA}_{0-45}$ and $\mathrm{DMA}_{45-50}$, among different years and locations was calculated separately. In addition, we further conducted a variance analysis using $\mathrm{DMA}_{0-45}$ and $\mathrm{DMA}_{45-50}$ in the three field trials to identify the effects of genotypes and environments on DMA.

The linear model was built as follows: $Y_{i j}=\mu+G_{i}+E_{j}+\varepsilon_{i j}$, in which $Y_{i j}$ is the observed value, $\mu$ is the population mean value of DMA, $G_{i}$ is the genetic effect of RIL, $E_{j}$ is the environmental effect of location, and $\varepsilon_{i j}$ is the random error. We also calculated the broadsense heritability $\left(h^{2}\right)$ using the analysis of variance as the formula: $h^{2}=\sigma_{\mathrm{G}}^{2} /\left(\sigma_{\mathrm{G}}^{2}+\sigma_{\mathrm{e}}^{2} / \mathrm{l}\right)$, where $\sigma_{\mathrm{G}}^{2}$ is the genetic variance, $\sigma_{\mathrm{e}}^{2}$ is the variance of random error and $/$ is total number of the environment.

\section{Construction of linkage map and QTL mapping}

We constructed a genetic linkage map using genome-wide SNPs obtained with Illumina's GoldenGate 3K Chip as previously reported (Liu et al. 2020). The Illumina GoldenGate 3k SNP chip was used to genotype all tested RILs, as well as two parental lines. SNPs meet the following criteria: 1) they show polymorphism between two parental lines; 2 ) they are homozygous in two parental lines, 844 and $807 ; 3$ ) they have a missing rate or heterozygous rate of $<20 \%$; and 4 ) they don't show distorted segregation in the RIL population (by chi-square test) were chosen to construct the linkage map. The maximum likelihood mapping method was used to construct the genetic linkage map using JoinMap4.0 (Ooijen 2006). We calculate the genetic distances between two adjacent SNPs by the Kosambi mapping method (Kosambi 1944).

For QTL analysis, $100 \mathrm{KDW}$ measured at $45 \mathrm{DAP}$ was taken as DMA during 0-45 DAP, termed as $\mathrm{DMA}_{0-45}$, while the difference between two sampling time points was calculated by the latter value minus the former one, and termed as $\mathrm{DMA}_{45-50}, \mathrm{DMA}_{50-55}$ and DMA $\mathrm{A}_{55-60}$, respectively. The QTL mapping was conducted for the three field trials. Phenotypic data were analyzed to detect all potential QTLs, using two replicates from each field trial separately, as well as their average values. Moreover, the method of best linear unbiased prediction (BLUP) (Robinson 1991) was used to predict expectations of DMA for each RIL across the three field trials.QTL mapping was conducted by QTL Cartographer2.5 (Basten et al. 1997) with the composite interval mapping method (Zeng 1994). The permutation test was set to 1000 times for QTL detection and with a logarithm of the odds (LOD) score $>2.5$ to affirm a putative QTL. A QTL that explains $>10 \%$ of the phenotypic variation $\left(R^{2}\right)$ was defined as a major QTL.

\section{Results}

\section{Dry matter accumulation in parents}

Of the two parents, 844 exhibits larger kernels than 807 , shown in grain length rather than grain width (Figure. 1-A, 1-B). Their $F_{1}$ hybrid kernels show a significant vigor both in length and width compared to the parental lines (Figure. 1-A, 1-B, 1-C). Consistently, 844 showed significant heavier dry matter accumulation than 807 when they were harvested at 50 days after pollination in Shandong. Considering that 45 DAP was a tipping point at which some of their derived RILs got physiologically matured in our previous study, we compared the DMA of parents by two periods, 0-45 DAP and 45-50 DAP. In each period, 844 showed significant higher DMA than 807, which suggested that the heavier weight of 844 was contributed by the fast DMA in both periods. However, whether same or different genetic factors are involved throughout the early and late stage is unknown (Figure. 1-D).

\section{The DMAs among the RIL population}

The DMAs at 45 and 50 DAP were measured by 100KDW in RIL population in the summer of 2014 at Shandong and in the winter of 2014 at Hainan. Two additional timepoints, 55 and 60 DAP in the summer of 2015 at Shandong, were supplemented. The DMAs in each period showed great variations among RILs (Appendix A-C). The $\mathrm{DMA}_{0-45}$ in each trail showed an approximately normal distribution, which suggested it as a typical quantitative trait. It ranged from $19.40 \mathrm{~g}$ to $33.4 \mathrm{~g}$ at Shangdong (2014), from $12.29 \mathrm{~g}$ to $33.34 \mathrm{~g}$ at Hainan (2014), and from $15.26 \mathrm{~g}$ to $31.51 \mathrm{~g}$ at Shangdong (2015). Among the three field trials, the $\mathrm{DMA}_{0-45}$ had significant $r$ values (Table 1), which suggested that $\mathrm{DMA}_{0-45}$ had relatively stable changes at each location and was less affected by the environments. In contrast to the substantial increase of $\mathrm{DMA}_{0-45}$, no $\mathrm{DMA}_{45-50}(0.00 \mathrm{~g})$ increase of some RILs in each trial indicated that they had reached PM at $45 \mathrm{DAP}$ and stopped grain filling thereafter. Though the $\mathrm{DMA}_{45-50}$ also showed an approximately normal distribution (Appendix A-B, B-B, C-B) and nearly the same magnitude of DMA changes, it had no significant $r$ values across the three 
field trials (Table 1), which suggested that environments had an impact on it. Astoundingly, active accumulation of dry weight was persistently detected after $50 \mathrm{DAP}$ at Shangdong (2015). The maximum values of $\mathrm{DMA}_{50-55}$ and $\mathrm{DMA}_{55-60}$ were $6.30 \mathrm{~g}$ and $6.35 \mathrm{~g}$, respectively. However, the $\mathrm{DMA}_{50-55}$ and $\mathrm{DMA}_{55-60}$ had skewed distributions, suggesting a large proportion of RILs had ceased their DMA by 50 DAP at Shangdong (2015) (Appendix C-C, C-D).

Based on the variance analysis, the genotypic variance components of $\mathrm{DMA}_{0-45}$ among different RILs were highly significant $(p<0.001)$, indicating the existence of genetic variability in RILs (Table 2). Moreover, the heritability of $\mathrm{DMA}_{0-45}$ was as high as $78.27 \%$. Besides for the genetic factors, the environments also have prominent influences since the variances of them were also significant. Although the variance of $\mathrm{DMA}_{45-50}$ among RILs was significant at $\mathrm{p}<0.01$ level, the heritability of $\mathrm{DMA}_{45-50}$ was only $39.84 \%$. By contrast, the $\mathrm{DMA}_{45-50}$ variation among different environments was the largest source of variation, indicating that $\mathrm{DMA}_{45-50}$ was largely affected by external factors. These results suggests that DWA promotes the kernel weight formation in a self-dominating way at early stage, but it is easily influenced by environmental conditions at late stage.

Table 2

Variance analysis of dry matter accumulation at 0-45 and 45-50 DAP

\begin{tabular}{|c|c|c|c|c|c|c|c|c|c|}
\hline DAP & Variance sources & df & ss & MS & F-value & $P$-value & EMS & Variance & $h^{2}$ \\
\hline \multirow[t]{3}{*}{$0-45$} & RILs & 128 & 2597.01 & 20.29 & 4.60 & $5.39 \mathrm{E}-21 * \star \star$ & $\sigma_{\mathrm{e}}^{2}+r \sigma_{\mathrm{G}}^{2}$ & 5.29 & \multirow[t]{3}{*}{$78.27 \%$} \\
\hline & Environments & 2 & 367.08 & 183.54 & 41.64 & $1.28 \mathrm{E}-15^{\star \star \star}$ & $\sigma_{\mathrm{e}}^{2}+n \sigma_{\mathrm{E}}^{2}$ & 1.39 & \\
\hline & Residuals & 182 & 802.15 & 4.41 & & & $\sigma_{\mathrm{e}}^{2}$ & 4.41 & \\
\hline \multirow[t]{3}{*}{$45-50$} & RILs & 127 & 364.75 & 2.87 & 1.51 & $0.006^{*}$ & $\sigma_{\mathrm{e}}^{2}+r \sigma_{\mathrm{G}}^{2}$ & 0.32 & \multirow[t]{3}{*}{$33.80 \%$} \\
\hline & Environments & 2 & 177.72 & 88.86 & 46.80 & $6.98 \mathrm{E}-17 * \star \star$ & $\sigma_{\mathrm{e}}^{2}+n \sigma_{\mathrm{E}}^{2}$ & 0.67 & \\
\hline & Residuals & 168 & 318.98 & 1.90 & & & $\sigma_{\mathrm{e}}^{2}$ & 1.90 & \\
\hline
\end{tabular}

QTL mapping of DMAs

The genetic linkage map used in our QTL mapping has been constructed previously (Liu et al. 2020). Here, we searched for relevant DMA QTLs across the entire maize genome. For the $\mathrm{DMA}_{0-45}$, a total of 13 QTLs were identified in three field trials, including four at Shandong in 2014, seven at Hainan in 2014, and six at Shandong in 2015 (Appendix D, E, F). These QTLs were distributed on all chromosomes except for chromosome 2 (Figure 2). The phenotypic variation that could be explained by a single QTL ranged from 7.11 to $23.64 \%$. Among them, four $\mathrm{DMA}_{0-45}$ QTLs, namely $q D M A 5.2$, qDMA6.4, qDMA7.2, and $q D M A 9.2$, were consistently detected on bins $5.05 / 07,6.05 / 08,7.03 / 04$, and 9.02 across two of three field trails, which explained $7.11-18.36 \%, 15.41-19.07 \%, 7.69-12.14 \%$, and $9.96-18.38 \%$ of the total phenotypic variation, respectively (Table 3 and Appendix G). Apart from qDMA6.4, the other three alleles with positive effects were all derived from the parent 844 . 
Table 3

The common-QTL detected in two of three filed trials

\begin{tabular}{|c|c|c|c|c|c|c|c|c|c|c|c|}
\hline Traits & $\begin{array}{l}\text { QTL- } \\
\text { Name }\end{array}$ & Locus\&time & DAP & $\mathbf{R}$ & Bins & $\begin{array}{l}\text { Flanking } \\
\text { SNP }\end{array}$ & $\begin{array}{l}\text { Physical } \\
\text { Location(Mb) }\end{array}$ & $\mathrm{Cl}(\mathrm{Mb})$ & LOD & $\mathrm{AE}(\mathrm{g})$ & $\mathrm{R}^{2}$ \\
\hline \multirow[t]{14}{*}{$\begin{array}{l}\text { DMA0- } \\
45\end{array}$} & \multirow[t]{3}{*}{ qDMA5.2 } & $\begin{array}{l}\text { Hainan } \\
\text { (2014) }\end{array}$ & $0-45$ & $\mathrm{R} 2$ & $\begin{array}{l}5.05- \\
5.07\end{array}$ & $\begin{array}{l}\text { SYN14522- } \\
\text { ZM004201- } \\
0285\end{array}$ & $\begin{array}{l}190.48- \\
207.72\end{array}$ & 17.24 & 2.86 & 1.14 & $7.11 \%$ \\
\hline & & $\begin{array}{l}\text { Shandong } \\
\text { (2015) }\end{array}$ & $0-45$ & $\mathrm{R} 2$ & $\begin{array}{l}5.06- \\
5.07\end{array}$ & $\begin{array}{l}\text { PZE- } \\
105154006- \\
\text { PZE- } \\
105165053\end{array}$ & $\begin{array}{l}204.38- \\
208.94\end{array}$ & 4.55 & 5.44 & 1.49 & $18.36 \%$ \\
\hline & & $\begin{array}{l}\text { Shandong } \\
\text { (2015) }\end{array}$ & $0-45$ & ave & $\begin{array}{l}5.06- \\
5.07\end{array}$ & $\begin{array}{l}\text { PZE- } \\
105154006- \\
\text { ZM004201- } \\
0285\end{array}$ & $\begin{array}{l}204.38- \\
207.72\end{array}$ & 3.34 & 4.05 & 1.15 & $13.41 \%$ \\
\hline & \multirow[t]{2}{*}{ qDMA6.4 } & $\begin{array}{l}\text { Shandong } \\
\text { (2014) }\end{array}$ & $0-45$ & $\mathrm{R} 2$ & $\begin{array}{l}6.05- \\
6.08\end{array}$ & $\begin{array}{l}\text { PZE- } \\
106080884- \\
\text { SYN24806 }\end{array}$ & $\begin{array}{l}137.83- \\
167.03\end{array}$ & 29.21 & 3.4 & -1.09 & $15.41 \%$ \\
\hline & & $\begin{array}{l}\text { Shandong } \\
\text { (2015) }\end{array}$ & $0-45$ & $\mathrm{R} 1$ & 6.05 & $\begin{array}{l}\text { SYN29972- } \\
\text { PHM5529.4 }\end{array}$ & $\begin{array}{l}137.83- \\
167.01\end{array}$ & 29.18 & 2.87 & -1.39 & $19.07 \%$ \\
\hline & \multirow[t]{4}{*}{$q D M A 7.2$} & $\begin{array}{l}\text { Hainan } \\
(2014)\end{array}$ & $0-45$ & ave & $\begin{array}{l}7.03- \\
7.04\end{array}$ & $\begin{array}{l}\text { PZA01714.1- } \\
\text { PZE- } \\
107121485\end{array}$ & $\begin{array}{l}134.14- \\
166.69\end{array}$ & 32.55 & 3.25 & 1.13 & $7.69 \%$ \\
\hline & & $\begin{array}{l}\text { Shandong } \\
\text { (2015) }\end{array}$ & $0-45$ & $\mathrm{R} 2$ & $\begin{array}{l}7.03- \\
7.04\end{array}$ & $\begin{array}{l}\text { PZA01714.1- } \\
\text { PZE- } \\
107121485\end{array}$ & $\begin{array}{l}134.14- \\
166.69\end{array}$ & 32.55 & 3.58 & 1.21 & $12.14 \%$ \\
\hline & & $\begin{array}{l}\text { Shandong } \\
\text { (2015) }\end{array}$ & $0-45$ & ave & 7.03 & $\begin{array}{l}\text { PZE- } \\
107077981- \\
\text { PZE- } \\
107081254\end{array}$ & $\begin{array}{l}133.03- \\
136.27\end{array}$ & 3.24 & 2.84 & 0.93 & $8.54 \%$ \\
\hline & & BLUP & $0-45$ & & $\begin{array}{l}7.03- \\
7.04\end{array}$ & $\begin{array}{l}\text { PZE- } \\
107072604- \\
\text { PZE- } \\
107121485\end{array}$ & 128.9-166.69 & 37.79 & 4.9 & 0.77 & $11.01 \%$ \\
\hline & \multirow[t]{5}{*}{ qDMA9.2 } & $\begin{array}{l}\text { Hainan } \\
(2014)\end{array}$ & $0-45$ & $\mathrm{R} 2$ & 9.02 & $\begin{array}{l}\text { SYN31970- } \\
\text { PZE- } \\
109019784\end{array}$ & $12.32-20.23$ & 7.91 & 4.35 & 1.48 & $11.18 \%$ \\
\hline & & $\begin{array}{l}\text { Hainan } \\
(2014)\end{array}$ & $0-45$ & ave & 9.02 & $\begin{array}{l}\text { SYN31970- } \\
\text { PZE- } \\
109019784\end{array}$ & $12.32-20.23$ & 7.91 & 5.44 & 1.54 & $13.89 \%$ \\
\hline & & $\begin{array}{l}\text { Shandong } \\
\text { (2015) }\end{array}$ & $0-45$ & $\mathrm{R} 1$ & 9.02 & $\begin{array}{l}\text { PZE- } \\
109013000- \\
\text { PZE- } \\
109019092\end{array}$ & $13.45-19.29$ & 5.84 & 4.07 & 1.21 & $14.06 \%$ \\
\hline & & $\begin{array}{l}\text { Shandong } \\
\text { (2015) }\end{array}$ & $0-45$ & $\mathrm{R} 2$ & 9.02 & $\begin{array}{l}\text { SYN31970- } \\
\text { PZE- } \\
109019784\end{array}$ & $12.32-20.23$ & 7.91 & 2.6 & 1.07 & $9.96 \%$ \\
\hline & & BLUP & $0-45$ & & 9.02 & $\begin{array}{l}\text { SYN31970- } \\
\text { PZE- } \\
109019784\end{array}$ & $12.32-20.23$ & 7.91 & 7.61 & 0.98 & $18.38 \%$ \\
\hline $\begin{array}{l}\text { DMA45- } \\
50\end{array}$ & & $\begin{array}{l}\text { Shandong } \\
\text { (2014) }\end{array}$ & $\begin{array}{l}45- \\
50\end{array}$ & $\mathrm{R} 1$ & $\begin{array}{l}1.05- \\
1.06\end{array}$ & $\begin{array}{l}\text { PZE- } \\
101126335- \\
\text { SYN28736 }\end{array}$ & $\begin{array}{l}159.95- \\
196.64\end{array}$ & 36.69 & 4.69 & 0.86 & $18.23 \%$ \\
\hline
\end{tabular}

DAP: days after pollination; Bins: the location of the QTL in the chromosomes; Flanking SNPs: the SNPs at the both sides of QTL; Physical Location (Mb): the physical location of the QTL; $\mathrm{Cl}(\mathrm{Mb})$ : size of confidential interval; $\mathrm{AE}$ : addictive effects; $\mathrm{R}^{2}$ : explained phenotypic variation. 


\begin{tabular}{|c|c|c|c|c|c|c|c|c|c|c|c|}
\hline Traits & $\begin{array}{l}\text { QTL- } \\
\text { Name }\end{array}$ & Locus\&time & DAP & $\mathbf{R}$ & Bins & $\begin{array}{l}\text { Flanking } \\
\text { SNP }\end{array}$ & $\begin{array}{l}\text { Physical } \\
\text { Location(Mb) }\end{array}$ & $\mathrm{Cl}(\mathrm{Mb})$ & LOD & $\mathrm{AE}(\mathrm{g})$ & $\mathrm{R}^{2}$ \\
\hline & $q D M A 1.2$ & $\begin{array}{l}\text { Shandong } \\
\text { (2014) }\end{array}$ & $\begin{array}{l}45- \\
50\end{array}$ & ave & $\begin{array}{l}1.05- \\
1.06\end{array}$ & $\begin{array}{l}\text { PZE- } \\
101093764- \\
\text { PZE- } \\
101146598\end{array}$ & 86.84-189.77 & 102.93 & 3.19 & 0.51 & $11.03 \%$ \\
\hline & & $\begin{array}{l}\text { Shandong } \\
(2015)\end{array}$ & $\begin{array}{l}45- \\
50\end{array}$ & $\mathrm{R} 2$ & 1.06 & $\begin{array}{l}\text { PZE- } \\
101135767- \\
\text { PZE- } \\
101153599\end{array}$ & $\begin{array}{l}175.64- \\
196.82\end{array}$ & 21.19 & 6.31 & 1.14 & $26.44 \%$ \\
\hline
\end{tabular}

DAP: days after pollination; Bins: the location of the QTL in the chromosomes; Flanking SNPs: the SNPs at the both sides of QTL; Physical Location (Mb): the physical location of the QTL; $\mathrm{Cl}(\mathrm{Mb})$ : size of confidential interval; $\mathrm{AE}$ : addictive effects; $\mathrm{R}^{2}$ : explained phenotypic variation.

With respect to $\mathrm{DMA}_{45-50}$, four QTLs were detected at Shandong in 2014, three at Hainan in 2014 and four at Shandong in 2015, and each could explain 8.49 to $26.44 \%$ of the total phenotypic variation. Among them, qDMA1.2 was detected repeatedly under different environmental conditions and explained $11.03-26.44 \%$ of the total phenotypic variation (Table 3 ). Likewise, this elite allele with positive effects was also derived from the parent 844 . When the late stage was extended to $60 \mathrm{DAP}, \mathrm{two} \mathrm{DMA}_{50-55}$ and seven $\mathrm{DMA}_{55-60}$ QTLs were detected (Appendix F). All the QTLs involved in DMA after 45 DAP distributed on all chromosomes except for chromosomes 7. Moreover, we performed a BLUP analysis of the DMA data sampled before and after 45 DAP to generate predictive values. Two of four common QTL, qDMA7.2 and $q D M A 9.2$ were also detected in BLUP analysis and can explain $11.01 \%$ and $18.38 \%$ of the total phenotypic variation, respectively (Table 3).

In addition to the above four consistent QTLs detected across the three field trials, other QTLs were consistently observed in two replicates within a single field trial, such as qDMA1.4, qDMA4.2, qDMA10.3 at Shangdong in 2014 and qDMA1.6 at Shangdong in 2015. Some other QTLs were detected at the early stage in one trial but at the late stage in another trail, such as $q D M A 8.3$ and qDMA5.1. These QTLs may rely on the environmental factors, like temperature or day length, thus we referred them as environmentdependent QTL.

To our surprise, no common DMA QTL was detected throughout the whole grain filling period. $q D M A 9.2$ was responsible for $\mathrm{DMA}_{0-45}$ and could be repeatedly detected at Hannan (2014) and Shangdong (2015), whereas, it could merely be found for $\mathrm{DMA}_{45-50}$ at the late stage. Likewise, $q D M A 1.2$ was consistently detected for $\mathrm{DMA}_{45-50}$ at Shangdong in 2014 and 2015 , but it had effect on $\mathrm{DMA}_{0-45}$ at Hannan (2014). This alteration may be happened by the external environments. On the contrary, qDMA5.2 and qDMA6.4 were only detected at the early stage. No matter how the environment changes, these QTLs function either before or after 45 DAP, indicating that DMA maybe contributed by different QTLs in a stage-dependent manner.

In order to confirm these five common QTLs, we performed a statistical analysis between RILs containing 807 alleles and 844 alleles in each QTL site (Figure 3). Consistent to the QTL effect in corresponding environment, qDMA5.2, qDMA6.4 and qDMA9.2 showed significance between two groups originate from 807 and 844 (Figure 3B, C, E). The significance of $q D M A 1.2$ could only be verified in the 2014SD-ave data set, but not the 2015SD-R2 data set (Figure 3A). However, the effect of qDMA7.2 is almost negligible since no significance has been detected here (Figure 3D). Based on the above results, qDMA5.2, qDMA6.4 and qDMA9.2 are more reliable and worthy for further gene mapping and cloning by advanced segregating populations, such as NIL or RIL-derived $F_{2}$ populations.

\section{Discussion}

Accurate phenotyping is a prerequisite for obtaining precise genomic loci for small-effect QTLs. Considering that environmental factors have substantial impacts on grain filling, we recorded the flowering time for each RIL and then selected those RILs with a similar silking time for further phenotyping. This similarity, along with adjusted sowing times, ensured that all RILs could be pollinated within a single day. The synchronous pollination guaranteed that all RILs in this analysis underwent the same grain filling duration to minimize environmental influence within a single field trial. Furthermore, we discarded the low-kernel-setting ears and sampled kernels from the middle of full-kernel-setting ears to eliminate the impact of kernel size on dry weight measurement. By transiently inactivating enzymes followed by complete drying, we improved the classical oven-dried method to obtain more precise kernel dry weight (Borrás et al. 2003; Sala et al. 2006; Pradoa et al. 2013). This is clearly reflected by the dynamic changes in the 100KDW of the four RILs analyzed from 20 to 50 DAP in our previous study. Four RILs all showed a steady and similar increase pattern of $100 \mathrm{KDW}$ during 20 to 
$45 \mathrm{DAP}$, which is in line with the dry matter accumulation pattern known in maize kernel. Moreover, the divergence of 100KDW was distinguishable among four RILs and $\mathrm{DMA}_{45-50}$ can determine if they have reached the PM stage at $45 \mathrm{DAP}$, indicating that $100 \mathrm{KDW}$ values collected at each sampling point were accurate and trustworthy. By performing a correlation analysis of the DMA across the three field trials (Table 1), we found a significant correlation among the $\mathrm{DMA}_{0-45}$ values across different environments, which suggested a high repeatability of $\mathrm{DMA}_{0-45}$. By contrast, there was no significant correlation among the $\mathrm{DMA}_{45-50}$ values across different filed trials, which indicated a great influence on DMA by environments at late gain-filling stage.

Grain dry weight is an essential trait with respect to grain yield. In our QTL analysis of dry weight accumulated during 0-45 DAP, a total of 13 QTL were separately detected in three field trials, some of them were consistently observed in at least two replicates in a single field trial. Moreover, four QTLs were constantly detected under different environments and two, qDMA7.2 and qDMA9.2, were also found with BLUP analysis. These results verified stable QTLs responsible for dry matter accumulation during the initial 45 days. Other QTL detected in solo trial may interact with specific environment and need further validation in the future.

According to the DMA curve of four tested RILs, some RILs may had reached the PM stage at 45 DAP, while others were still accumulating subsequently. This proved by a normal distribution of $\mathrm{DMA}_{45-50}$ in RIL population under three different sampling points (Appendix A-B, B-B, C-B). By contrast, $\mathrm{DMA}_{50-55}$ and $\mathrm{DMA}_{55-60}$ at Shandong in 2015 showed deviated distributions because of halted or slowed accumulation of dry weight (Appendix C-C, C-D), which indicated that a majority of RILs were approaching PM or had reached PM stage at 50 or 55 DAP. Because the difference of $100 \mathrm{KDW}$ between two adjacent sampling times after 45 DAP reflects the grain development in the late stage, we also did QTL analysis with $\mathrm{DMA}_{45-50}$ in three different environments and $\mathrm{DMA}_{50-55}, \mathrm{DMA}_{55-60}$ at Shangdong in 2015. A total of 10 QTLs of $D_{M A} A_{450}$ were detected, however, only qDMA1.2 can be reproduced between different environments. When taking $\mathrm{DMA}_{50-55}$ and $\mathrm{DMA}_{55-60}$ as traits in 2015 at Shangdong, qDMA1.6 was detected repeatedly. Comparing the $\mathrm{DMA}_{0-45}$ and $\mathrm{DMA}_{45-50}$ QTLs in different field trials, we found that some QTL related to $\mathrm{DMA}_{0-45}$ at one place, but associated with $\mathrm{DMA}_{45-50}$ at another place. For instance, qDMA9.2 was detected for $\mathrm{DMA}_{0-45}$ at Hainan in 2014 and at Shangdong in 2015, whereas it was found for $\mathrm{DMA}_{45-50}$ at Shangdong in 2014 (Figure 2). Likewise, qDMA1.2 was consistently detected for $\mathrm{DMA}_{0-45}$ at Hainan in 2014, but it was identified for $\mathrm{DMA}_{45-50}$ at Shangdong both in 2014 and 2015. One possible reason is that they may function at the stage approaching the PM. Once the external environment changes, their role may be found either in the early or in the late stage. Therefore, further subdivision of the stages for dynamic DMA will facilitate the depth resolution of grain yield composition.

Although a long GFD could increase the grain yield, however, it may lead to high grain water content at harvest, which would ruin the mechanical harvest and spend more cost of drying. We suggest that QTLs involved in grain yield with a faster GFR rather than a prolonged GFD are preferred in maize genetic improvement in the future. Since all the RILs were pollinated by the same parental line 807 , one possibility that can't be ruled out is that QTL effect in this study may resulted from the interaction between two parents. Even so, such QTL can still be applied due to the predominant utilization of heterosis in maize breeding. In the current study, we detected five common loci related to $\mathrm{DMA}_{0-45}$ or $\mathrm{DMA}_{45-50}$, namely $q D M A 7.2, q D M A 6.4, q D M A 9.2, q D M A 5.2$ and $q D M A 1.2$. Comparing with previous results, we found these QTLs reside at hotspot chromosomal bins, including bin 5.05-5.07, 7.02-7.04, and 9.00-9.04 (Yan et al. 2006; Li et al. 2010; Guo et al. 2011; Liu et al. 2011; Li et al. 2013; Zhang et al. 2013; Liu et al. 2014; Sa et al. 2015; Raihan et al. 2016; Zhang et al. 2016). As a faster grain filling rate may contribute to a higher dry matter accumulation at early stage, consistent QTL related to grain filling uncovered by different mapping populations could be referenced for further confirmation. These $\mathrm{DMA}_{0-45}$ QTLs would be most valuable for subsequent breeding of maize varieties with increased grain yield.

\section{Conclusion}

A number of DMA QTLs were detected at both early and late growth stages from the RIL population. For DMA before 45 DAP $\left(\mathrm{DMA}_{0-45}\right)$, four QTLs, $q D M A 5.2, q D M A 6.4, q D M A 7.2$, and $q D M A 9.2$, were consistently detected in at least two of three field trials. For DMA after 45 DAP $\left(\mathrm{DMA}_{45-50}, \mathrm{DMA}_{50-55}\right.$ and $\left.\mathrm{DMA}_{55-60}\right), q D M A 1.2$ was detected for $\mathrm{DMA}_{45-50}$ at Shandong for two years continuously. Our study speculated that the genetic control of DMA acts in a stage-dependent manner. It also provides a basis for further fine-mapping and cloning of genes related to grain yield with fast GFR in early or late stages.

\section{Abbreviations}


DMA, dry matter accumulation; 100KDW, 100-kernel dry weight; PM, physiological maturity; QTL, quantitative trait locus; RIL, recombinant inbred line; BLUP, best linear unbiased prediction; DAP, days after pollination; GFD, grain filling duration; GFR, grain filling rate; $h^{2}$, broad-sense heritability; $\mathrm{IF}_{2}$, Immortalized $\mathrm{F}_{2}$; LOD, logarithm of the odds; a minimum period for physiological maturity (MPPM)

\section{Declarations}

\section{Competing Interests}

The authors have no relevant financial or non-financial interests to disclose.

\section{Author Contributions}

Jianju Liu participated in the whole experimental process. Liu Baoshen prepared the RIL population. Hui Yu performed the maize cultivation and phenotyping. Saihua Chen and Mingliang Xu designed, supervised and guided the experiments. Saihua Chen was also involved in the analysis of results. Jianju Liu wrote the draft manuscript. Saihua Chen and Mingliang Xu revised the manuscript. Both authors read and approved the final manuscript.

\section{Data Availability}

The original data generated during the current study are available from the corresponding author on reasonable request.

\section{Acknowledgements}

We are grateful to Qingcai Liu who provided the GoldenGate 3K SNP chip. This work was financially supported by the National Natural Science Foundation of China (Grant No. 31872870), Jiangsu Agricultural Science and Technology Innovation Fund (CX(21)3100), Jiangsu Natural Science Research Project (20KJA210001) and a Project Funded by the Priority Academic Program Development of Jiangsu Higher Education Institutions (PAPD).

\section{References}

1. Basten CJ, Weir BS, Zeng ZB (1997) QTL cartographer: a reference manual and tutorial for QTL mapping. Department of Statistics, North Carolina State University, Raleigh

2. Baute T (2002) Agronomy guide for field crops (OMAFRA Publication 811). Ontario Ministry of Agriculture Food and Rural Affairs (OMAFRA), Ontario

3. Bewley JD (1994) Seeds: germination, structure, and composition. Seeds: physiology of development and germination. Plenum Press, New York, pp 1-31

4. Borrás L, Westgate ME, Otegui ME (2003) Control of kernel weight and kernel water relations by post-flowering source-sink ratio in maize. Ann Bot 91:857-867 https://doi.org/10.1093/aob/mcg090

5. Borrás L, Zinselmeier C, Senior ML, Westgate ME, Muszynski MG (2009) Characterization of grain-filling patterns in diverse maize germplasm. Crop Sci 49:999-1009 https://doi.org/10.2135/cropsci2008.08.0475

6. Gambín BL, Borrás L, Otegui ME (2008) Kernel weight dependence upon plant growth at different grain-filling stages in maize and sorghum. Aust J Agric Res 59:280-290 https://doi.org/10.1071/AR07275

7. Gasura E, Setimela P, Edema R, Gibson PT, Okori P, Tarekegne A (2013) Exploiting grain-filling rate and effective grain-filling duration to improve grain yield of early-maturing maize. Crop Sci 53:2295-2303 http://dx.doi.org/10.2135/cropsci2013.01.0032

8. Geng A, Yang J, Zhang Z, Zhang J, Li R (2016) Discuss about the current situation and future of corn harvest machinery about domestic and abroad. Journal of Agricultural Mechanization Research 38:251-257. (in Chinese)

9. Guo J, Chen Z, Liu Z, Wang B, Song W, Li W, Chen J, Lai J (2011) Identification of genetic factors affecting plant density response through QTL mapping of yield component traits in maize (Zea mays L.). Euphytica 182:409-422 https://doi.org/10.1007/s10681- 
011-0517-8

10. Kang MS, Zuber MS, Colbert TR, Horrocks RD (1986) Effects of certain agronomic traits on and relationship between rates of grain-moisture reduction and grain fill during the filling period in maize. Field Crops Res 14:339-

347 https://doi.org/10.1016/0378-4290(86)90068-7

11. Kebebe AZ, Reid LM, Zhu X, Wu J, Woldemariam T, Voloaca C, Xiang K (2015) Relationship between kernel drydown rate and resistance to Gibberella ear rot in maize. Euphytica 201:79-88 https://doi.org/10.1007/s10681-014-1185-2

12. Kosambi DD (1944) The estimation of map distance from recombination values. Ann Eugen 12:172175 https://doi.org/10.1007/978-81-322-3676-4_16

13. Ku LX, Zhao WM, Zhang J, Wu LC, Wang CL, Wang PA, Zhang W, Chen YH (2010) Quantitative trait loci mapping of leaf angle and leaf orientation value in maize (Zea mays L.). Theor Appl Genet 121:951-959 https://doi.org/10.1007/s00122-010-1364-z

14. Li C, Li Y, Sun B, Peng B, Liu C, Liu Z, Yang Z, Li Q, Tan W, Zhang Y, Wang D, Shi Y, Sun Y, Wang T, Li Y (2013) Quantitative trait loci mapping for yield components and kernel-related traits in multiple connected RIL populations in maize. Euphytica 193:303316 https://doi.org/10.1007/s10681-013-0901-7

15. Li M, Guo X, Zhang M, Wang X, Zhang G, Tian Y, Wang Z (2010) Mapping QTL for grain yield and yield components under high and low phosphorus treatments in maize (Zea mays L.). Plant Sci 178:454-462 https://doi.org/10.1016/j.plantsci.2010.02.019

16. Li XJ, Pan ZD (2005) A study on the grain filling characteristic of different weight wheat. Review of China Agricultural Science \& Technology 7:26-30. (in Chinese)

17. Li X, Li YX, Chen L, Wu X, Qin W, Song Y, Zhang D, Wang T, Shi Y (2016) Fine mapping of qKW7, a major QTL for kernel weight and kernel width in maize, confirmed by the combined analytic approaches of linkage and association analysis. Euphytica 210:221232 https://doi.org/10.1007/s10681-016-1706-2

18. Liu J, Yu H, Liu Y, Deng S, Liu Q, Liu B, Xu M (2020) Genetic dissection of grain water content and dehydration rate related to mechanical harvest in maize. BMC Plant Biol 20:1-16 https://doi.org/10.1186/s12870-020-2302-0

19. Liu Y, Wang L, Sun C, Zhang Z, Zheng Y, Qiu F (2014) Genetic analysis and major QTL detection for maize kernel size and weight in multi-environments. Theor Appl Genet 127:1019-1037 https://doi.org/10.1007/s00122-014-2276-0

20. Liu ZH, Ji HQ, Cui ZT, Wu X, Duan LJ, Feng XX, Tang JH (2011) QTL detected for grain-filling rate in maize using a RIL population. Mol Breed 27:25-36 https://doi.org/10.1007/s11032-010-9410-8

21. Ooijen JWV (2006) JoinMap 4 Software for the calculation of genetic linkage maps in experimental populations. Kyazma BV, Wageningen, Netherlands

22. Prado SA, López CG, Gambín BL, Abertondo VJ, Borrás L (2013) Dissecting the genetic basis of physiological processes determining maize kernel weight using the IBM (B73× Mo17) Syn4 population. Field Crops Res 145:3343 https://doi.org/10.1016/j.fcr.2013.02.002

23. Raihan MS, Liu J, Huang J, Guo H, Pan Q, Yan J (2016) Multi-environment QTL analysis of grain morphology traits and fine mapping of a kernel-width QTL in Zheng58× SK maize population. Theor Appl Genet 129:14651477 https://doi.org/10.1007/s00122-016-2717-z

24. Robinson GK (1991) That BLUP is a good thing: the estimation of random effects. Statist Sci 6:15-32

25. Sa KJ, Park JY, Woo SY, Ramekar RV, Jang CS, Lee JK (2015) Mapping of QTL traits in corn using a RIL population derived from a cross of dent corn× waxy corn. Genes Genomics 37:1-14 https://doi.org/10.1007/s13258-014-0223-8

26. Sala RG, Andrade FH, Camadro EL, Cerono JC (2016) Quantitative trait loci for grain moisture at harvest and field grain drying rate in maize (Zea mays L.). Theor Appl Genet 112:462-471 https://doi.org/10.1007/s00122-005-0146-5

27. Tang J, Yan J, Ma X, Teng W, Wu W, Dai J, Dhillon BS, Melchinger AE, Li J (2010) Dissection of the genetic basis of heterosis in an elite maize hybrid by QTL mapping in an immortalized F2 population. Theor Appl Genet 120:333340 https://doi.org/10.1007/s00122-009-1213-0

28. Wang G, Kang MS, Moreno O (1999) Genetic analyses of grain-filling rate and duration in maize. Field Crops Res 61:211222 https://doi.org/10.1016/S0378-4290(98)00163-4

29. Yan JB, Tang H, Huang YQ, Zheng YL, Li JS (2016) Quantitative trait loci mapping and epistatic analysis for grain yield and yield components using molecular markers with an elite maize hybrid. Euphytica 149:121-131 https://doi.org/10.1007/s10681-0059060-9 
30. Yin S, Li P, Xu Y, Liu J, Yang T, Wei J, Xu SH, Yu JJ, Fang HM, Xue L, Hao DR, Yang ZF, Xu CW (2020) Genetic and genomic analysis of the seed-filling process in maize based on a logistic model. Heredity 124:122-134 https://doi.org/10.1038/s41437-019-0251-X

31. Zeng ZB (1994) Precision mapping of quantitative trait loci. Genetics 136:14571468 https://doi.org/10.1093/genetics/136.4.1457

32. Zhang J, Guo J, Liu Y, Zhang D, Zhao Y, Zhu L, Huang Y, Zhang Z, Chen J (2016) Genome-wide association study identifies genetic factors for grain filling rate and grain drying rate in maize. Euphytica 212:201-212 https://doi.org/10.1007/s10681-016-1756-5

33. Zhang Z, Liu Z, Cui Z, Hu Y, Wang B, Tang J (2013) Genetic analysis of grain filling rate using conditional QTL mapping in maize. PLoS ONE 8:e56344 https://doi.org/10.1371/journal.pone.0056344

\section{Figures}

a

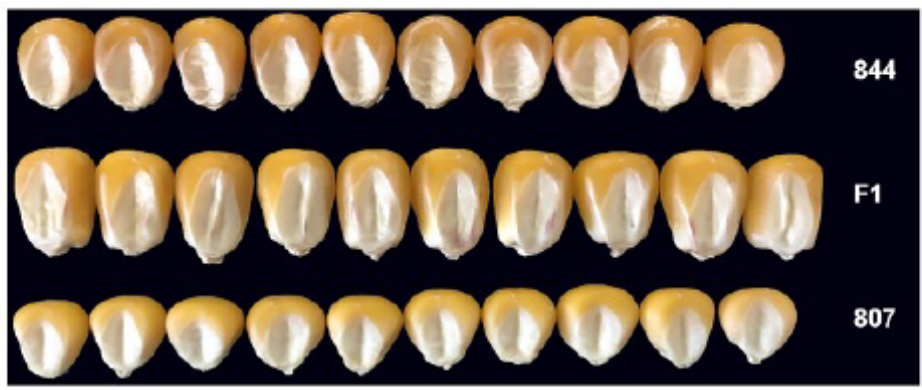

d

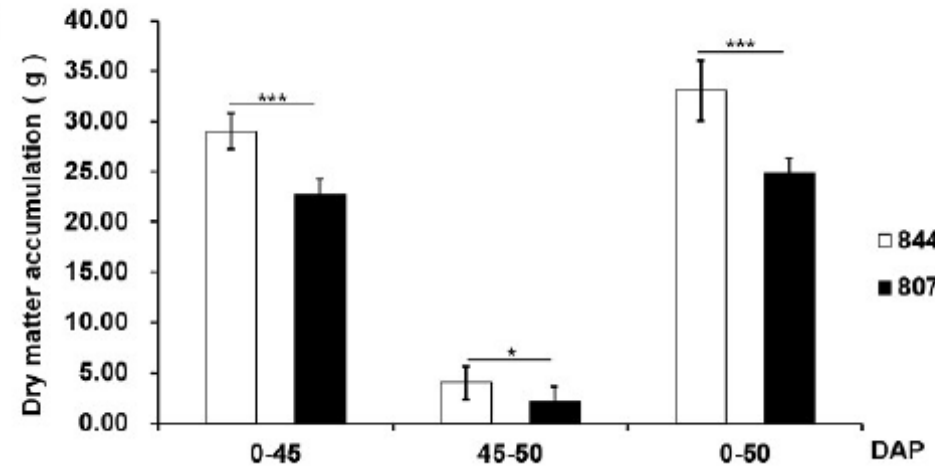

b

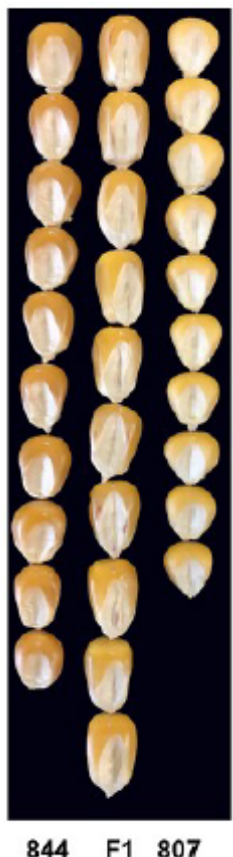

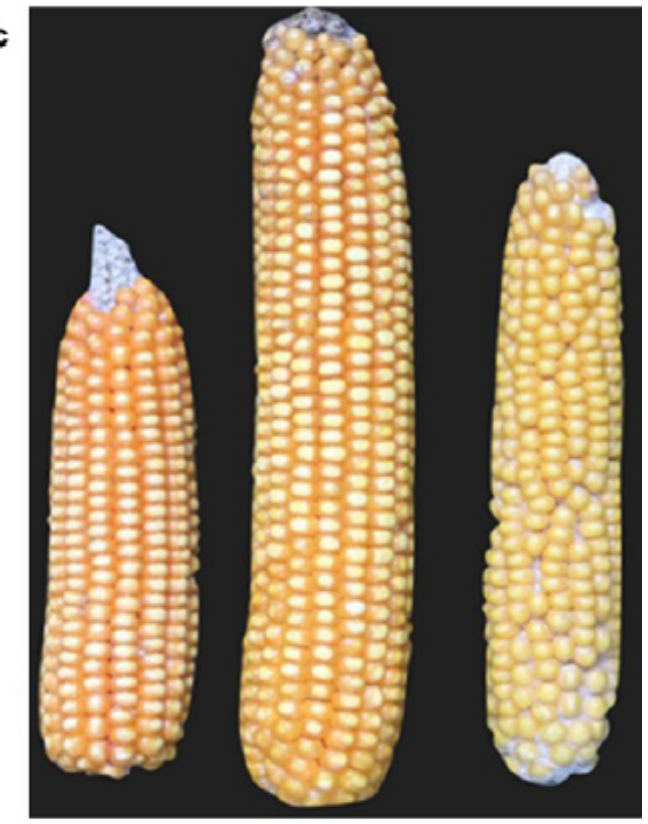

844
F1
807

\section{Figure 1}

Comparison of the shape of kernels and ears among inbred lines 844,807 , and their $F_{1}$ hybrid and the comparison of dry matter during different development stages. A, Horizontal arrangement of the kernels, B, Vertical arrangement of the kernels, C, shapes of the ears. D, The comparison of dry matter accumulation between 844 and 807 during different grain filling stages, Values are the dry matter accumulation \pm SD. Statistical significance was determined using Student's t-test: ${ }^{*} \mathrm{P}<0.05,{ }^{\star \star} \mathrm{P}<0.01,{ }^{\star \star *} \mathrm{P}<0.001$.

Figure 2

The distribution of QTLs on 10 chromosomes.

Ch1-Ch10: represent the chromosomes 1 to 10. Graphics with different colors and shapes represent QTLs located in different years, locations and sampling times. See the legend for details. DAP: days after pollination 


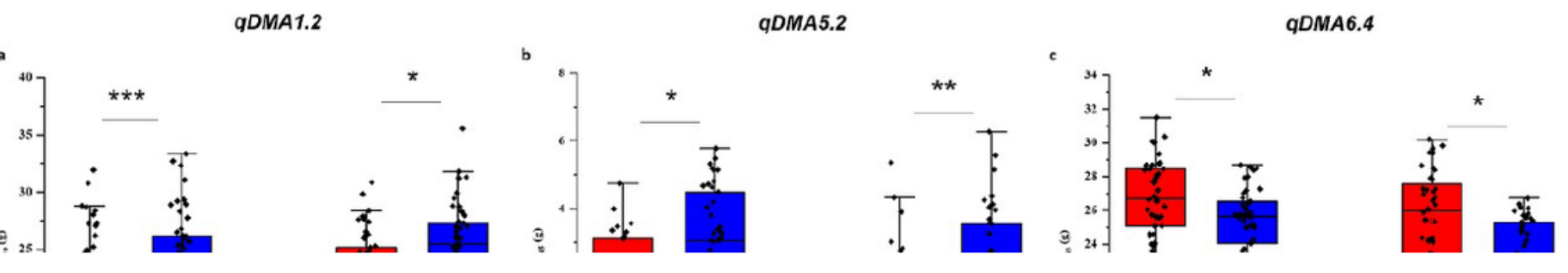

\section{Figure 3}

The statistical analysis of five common QTL's effect.

Two data sets corresponding to each common QTL were selected to our statistical analysis. Red box indicates DMA data from the RILs owning the same allele with 807; Blue box shows DMA data from the RILs with the 844 allele. Black dots represent the values of different RILs retrieved from repeat 1(R1), repeat 2 (R2) or average (ave) at Shandong in 2014 (2014SD), at Hainan in 2014 (2014HN) and at Shandong in 2015 (2015SD). The significance $\left({ }^{\star} P<0.05,{ }^{*} P<0.01,{ }^{\star} * \star P<0.001\right)$ was calculated by Student's $t$ test.

\section{Supplementary Files}

This is a list of supplementary files associated with this preprint. Click to download.

- Appendix.docx 